\title{
Effects of Imipramine and Lithium on the Expression of Hippocampal Wnt 3a and Cyclin D1 in ACTH-Treated Rats
}

\author{
Yoshihisa Kitamura1 ${ }^{*}$, Hiromi Hayashi', Yuka Onoue ${ }^{1}, K^{1}$ eiko Kuwatsuka ${ }^{1}$, \\ Ayaka Miyake1, Ikuko Miyazaki², Masato Asanuma², Toshiaki Sendo1 \\ ${ }^{1}$ Department of Clinical Pharmacy, Graduate School of Medicine, Dentistry and Pharmaceutical Sciences, \\ Okayama University, Okayama, Japan \\ ${ }^{2}$ Department of Brain Science, Graduate School of Medicine, Dentistry and Pharmaceutical Sciences, \\ Okayama University, Okayama, Japan \\ Email: ${ }^{*}$ kitamu-y@cc.okayama-u.ac.jp
}

Received 9 September 2014; revised 24 October 2014; accepted 9 November 2014

Academic Editor: Ankur Sachdeva, P.G.I.M.E.R, Dr RML Hospital, India

Copyright (C) 2014 by authors and Scientific Research Publishing Inc.

This work is licensed under the Creative Commons Attribution International License (CC BY). http://creativecommons.org/licenses/by/4.0/

cC) (i) Open Access

\section{Abstract}

We have shown previously that chronic administration of adrenocorticotropic hormone (ACTH) causes a significant decrease in hippocampal cell proliferation and neurogenesis. This effect in rats treated chronically with ACTH was not influenced by the chronic administration of imipramine, but was reversed by coadministration of imipramine and lithium. The present study was undertaken to further characterize the mechanism underlying the effect of imipramine and lithium on hippocampal cell proliferation and neurogenesis, by investigating the effects of treatment on the expression of brain-derived neurotrophic factor (BDNF), total cyclic adenosine monophosphate response element-binding protein (CREB), and phosphorylated CREB (pCREB) of the CREB signaling system, as well as Wnt 3a and cyclin D1 of the Wnt signaling pathway in the hippocampus of saline- and ACTH-treated rats. ACTH treatment significantly decreased the expression of cyclin D1. Treatment with imipramine and lithium increased the expression of cyclin D1 in ACTH-treated rats. However, the expression of BDNF, CREB, pCREB, and Wnt 3a did not change in either salinetreated or ACTH-treated rats. These findings suggest that the antidepressant effect of imipramine and lithium in ACTH-treatment-resistant rats may be attributed, at least in part, to an enhancement of cyclin D1 expression.

\footnotetext{
"Corresponding author.
} 
Keywords

\section{Adrenocorticotropic Hormone, Imipramine, Lithium, Cyclin D1, Cell Proliferation}

\section{Introduction}

We already reported that the effect of tricyclic antidepressants to decrease immobility is blocked by repeated adrenocorticotropic hormone (ACTH) treatment in the forced swim test, a behavioral test widely used as a predictor of antidepressant activity [1]. This blocking of the immobility time-decreasing effect of imipramine is reversed by the coadministration of lithium and imipramine [1]. Furthermore, electroconvulsive therapy is an effective treatment for patients with treatment-resistant depression [2]. Repeated electroconvulsive stimulation was shown to significantly decrease the immobility time in the forced swim test of ACTH-treated rats [3]. Chronic treatment of rats with ACTH may be an effective model of tricyclic antidepressant treatment-resistant depression [1].

Chronic treatment with antidepressants may increase cell proliferation and survival and reverse stress-induced decreases in hippocampal cell proliferation and neurogenesis [4] [5]. The ability to promote hippocampal neurogenesis is a feature of both classical antidepressants, such as tricyclic drugs, and selective serotonin re-uptake inhibitors [6] [7]. Moreover, hippocampal cell proliferation and neurogenesis may be key factors in the actions of antidepressant drugs. On the other hand, wepreviously reported that treatment with imipramine and lithium affects progenitors that have a limited capacity for cell proliferation [8] [9]. In a previous study, the chronic administration of ACTH (100 $\mu \mathrm{g} / \mathrm{rat}$ subcutaneously for 14 days) was found to significantly decrease the number of 5-bromo-2'-deoxyuridine and Ki-67 (an endogenous marker of cell proliferation)-positive cells compared with control values in the subgranular zone (SGZ) of the hippocampal dentate gyrus [8] [9]. This effect of ACTH treatment was not influenced by the chronic administration of imipramine, but was reversed by the coadministration of imipramine and lithium for 14 days [9]. Thus, these results suggest that imipramine and lithium improve the efficacy of treatment for resistant depression by triggering cell proliferation.

Brain-derived neurotrophic factor (BDNF) has also attracted attention due to key role in mediating neural regeneration, synaptic transmission, synaptic plasticity, and neurogenesis [10] [11]. Furthermore, low levels of BDNF protein have been implicated in clinical mood disorders and animal models of mood disorders [12] [13]. On the other hand, cyclic adenosine monophosphate response element-binding protein (pCREB) may mediate neuroplasticity. Furthermore, BDNF expression is regulated in part by pCREB. The unpredictable chronic mild stress model is an animal model of depression, which showedthe down-regluation of BDNF, CREB, and neurogenesis [14].

Cyclin D1 is positive regulator of cellular progression though the G1 phase of the cell cycle [15] [16]. Earlier reports suggested that cyclin D1 expression is significantly correlated with $\beta$-catenin expression [17] [18]. $\beta$ catenin is a key downstream effector of the $\mathrm{Wnt} / \beta$-catenin signaling pathway regulating cell proliferation [19]. Studies have indicated that blocking of the Wnt signaling pathway perturbs progenitor cell proliferation and causes a marked reduction in hippocampal development [20]. We reported that the antidepressant effect of a 5- $\mathrm{HT}_{1 \mathrm{~A}}$ receptor agonist, (+)-8-OH-DPAT, in ACTH-treated rats may be attributed to an enhancement of hippocampal cell proliferation, at least in part due to an enhancement of cyclin D1 expression.

In the present study, we examined the effect of treatment with imipramine and lithium on the expressions of BDNF, CREB, and Wnt 3a, a strong nuclear signal for cyclin D1 transcription, to elucidate the involvement of CREB-BDNF and Wnt/ $\beta$-catenin signaling in hippocampal cell proliferation in ACTH-treated rats.

\section{Materials and Methods}

\subsection{Animals}

Wistar rats (Charles River, Yokohama, Japan) with initial weights of 220 - 230 g were utilized. The rats were housed in pairs in an air-conditioned room $\left(23^{\circ} \mathrm{C} \pm 1^{\circ} \mathrm{C}\right.$ with approximately $60 \%$ humidity) under a constant light-dark cycle (lights on 07:00-19:00 hours) and fed standard laboratory food and tap water. All experiments were conducted according to the guidelines for animal experimentation at Okayama University Medical School. All efforts were made to minimize the number of animals used and their degree of suffering. 


\subsection{Drugs}

The following drugs were used: imipramine hydrochloride (Sigma), lithium carbonate (Taisho Pharmaceutical, Tokyo, Japan) and ACTH-(1-24)-zinc (ACTH; Cortrosyn Z: Daiichi-Sankyo, Tokyo, Japan). Imipramine was dissolved in saline. Lithium was suspended in a $0.5 \%$ methylcellulose solution. The rats were administered imipramine and lithium at a dose of $2 \mathrm{~mL} / \mathrm{kg}$ body weight for 14 days. ACTH was injected subcutaneously once daily (09:00 to 10:00 hours) for 14 days at $100 \mu \mathrm{g} / \mathrm{rat}$ (injection volume $=0.2 \mathrm{~mL} / \mathrm{rat}$ ). The control rats received an equivalent volume of vehicle (saline $0.2 \mathrm{~mL} /$ rat, subcutaneous) for the same period of time.

\subsection{Western Blot Analysis}

Nuclear protein was extracted from rat hippocampal tissues one day after the last dose of ACTH, imipramine, and lithium. Homogenized samples were loaded on $1 \%$ sodium dodecyl sulfate-containing polyacrylamide gels and blotted onto polyvinylidene difluoride membranes (Hybond-P, Amersham, Buckinghamshire, UK). Blots were incubated with rabbit anti-BDNF polyclonal antibody (1:200 dilution, Santa Cruz Biotechnology, Santa Cruz, CA, USA); rabbit anti-phospho CREB (Ser133) monoclonal antibody (1:1000 dilution, Santa Cruz Biotechnology, Santa Cruz, CA, USA) or rabbit anti-CREB polyclonal antibody (1:250 dilution, Santa Cruz Biotechnology, Santa Cruz, CA, USA); rabbit anti-Wnt 3a polyclonal antibody (1:1000 dilution, Millipore, Billerica, MA, USA); or rabbit anti-cyclin D1 polyclonal antibody (1:200 dilution, Santa Cruz Biotechnology, CA, USA). The blots were then reacted with the corresponding secondary antibody conjugated to horseradish peroxidase. After washing with $20 \mathrm{mM}$ Tris-buffered saline containing $0.1 \%$ Tween 20, blots were developed using the ECL Western blotting detection system (Amersham, Buckinghamshire, UK). Images were quantified using a FUJIFILM Luminescent Image Analyzer LAS-3000 (FUJIFILM, Tokyo, Japan) and Multi Gauge (v3.0) software. For quantitative analysis, the ratio each specific protein signal (relative chemiluminescence unit) to that of constitutively expressed $\alpha$-tubulin protein was calculated to normalize for loading and transfer artifacts.

\subsection{Statistical Analysis}

Data analysis was performed blindly with regard to treatment. Quantitative data were analyzed by one-way analysis of variance, followed by Tukey's test. Data are expressed as mean \pm S.E.M. Values of $P<0.05$ were considered statistically significant.

\section{Results}

\subsection{Effects of Chronic Treatment with Imipramine and Lithium for 14 Days on Hippocampal Expression of Mature-BDNF in Saline- and ACTH-Treated Rats}

It has been reported that BDNF plays an important role in development, neural regeneration, synaptic transmission, synaptic plasticity and neurogenesis, and mossy fiber sprouting [11] [21]. Treatment with ACTH for 14 days did not change the hippocampal expression of mature-BDNF in saline- and ACTH-treated rats. In addition, treatment with imipramine and lithium did not affect hippocampal BDNF expression in either saline- or ACTHtreated rats (Figure 1).

\subsection{Effects of Chronic Treatment with Imipramine and Lithium for 14 Days on Hippocampal Expression of CREB and pCREB in Saline- and ACTH-Treated Rats}

Western blotting was performed to examine whether concomitant treatment with imipramine and lithium changes the expression of CREB and PCREB in the hippocampus. Treatment with ACTH for 14 days did not change the hippocampal expression of CREB or pCREB in saline- or ACTH-treated rats. In addition, the hippocampal expression of CREB and pCREB was not affected by treatment with imipramine and lithium in either saline- or ACTH-treated rats (Figure 2).

\subsection{Effects of Chronic Treatment with Imipramine and Lithium for 14 Days on Hippocampal Expression of Wnt 3a and Cyclin D1 in Saline- and ACTH-Treated Rats}

$\mathrm{Wnt} / \beta$-catenin signaling is an evolutionarily conserved pathway that plays a major role in various developmental 


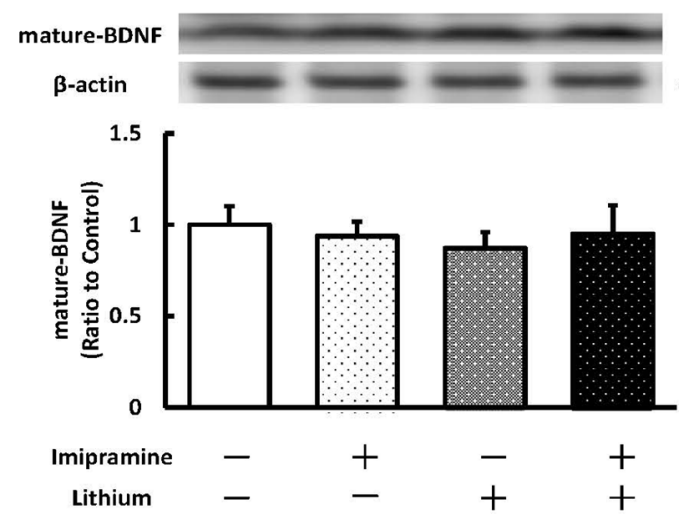

(a)
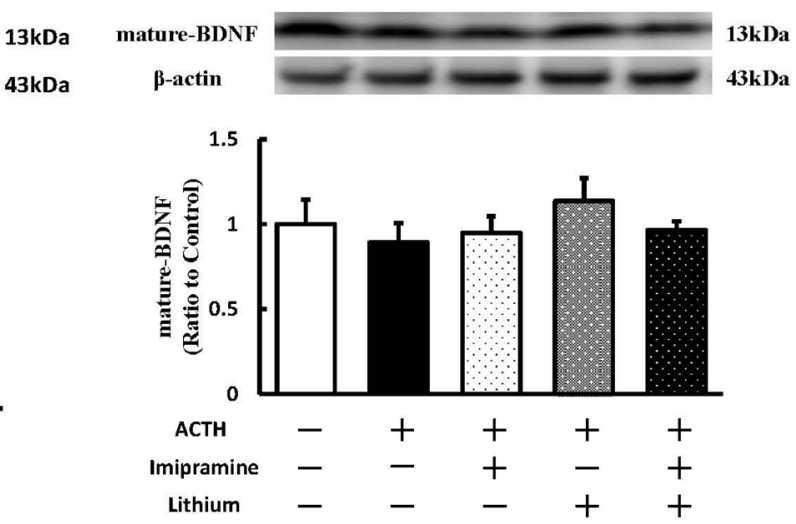

(b)

Figure 1. Effects of treatment with imipramine and lithium for 14 days on mature-BDNF protein levels in the hippocampus in saline-treated (a) and ACTH-treated rats (b). Each column is expressed as the mean \pm S.E.M.; $n=6-8$ per group.

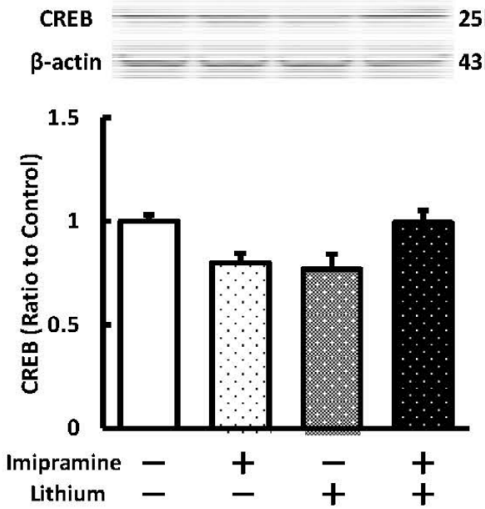

(a)
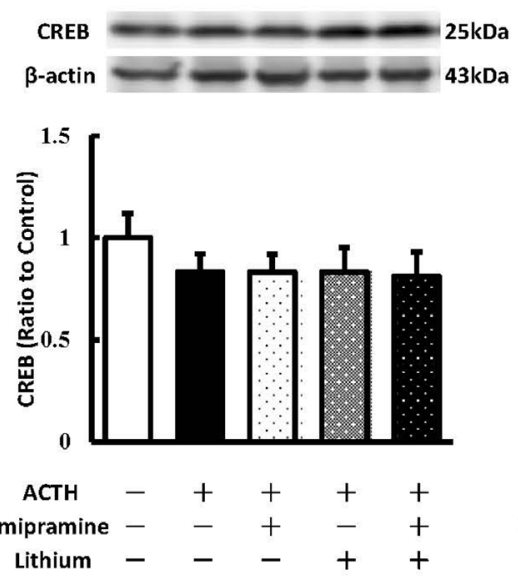

(c)
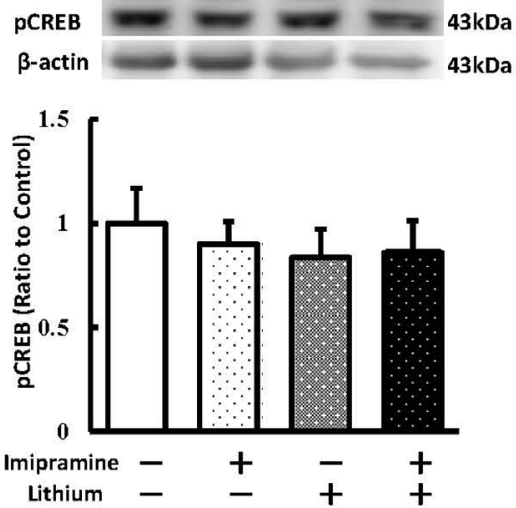

(b)
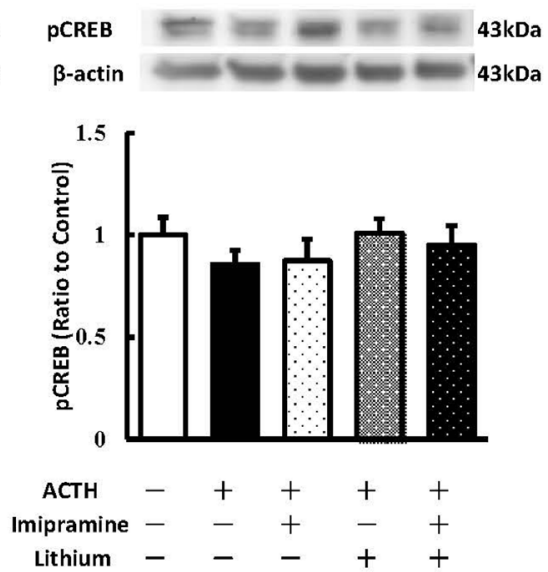

(d)

Figure 2. Effects of treatment with imipramine and lithium for 14 days on CREB (a) (c) and pCREB (b) (d) protein levels in the hippocampus of saline-treated and ACTHtreated rats. Each column is expressed as the mean \pm S.E.M.; $n=6$ - 8 per group.

processes including cell proliferation and differentiation. To confirm this finding and further examine the effect of imipramine and lithium on Wnt 3a and cyclin D1 protein levels, we collected hippocampal tissues from sa- 
line- and ACTH-treated rats and performed Western blotting. Cyclin D1, but not Wnt 3a, protein levels were significantly decreased in ACTH-treated rats compared to saline-treated controls (Figure 3(b), Figure 4(b)). Repeated imipramine and lithium treatment prevented the reduction of cyclin D1 protein levels in the hippocampus of ACTH-treated rats (Figure 3(b)). However, cyclin D1 and Wnt 3a levels did not change as a result of treatment with imipramine and lithium in saline-treated rats (Figure 3(a), Figure 4(a)).

\section{Discussion}

Previous studies using behavioral screening for antidepressant activity in rodents have shown that the decrease in immobility induced by single and repeated administrations of imipramine and desipramine could be blocked by the repeated (14 days) administration of ACTH [1]. Lithium has been shown to be effective in the treatment of several forms of affective disorders, such as treatment-resistant depression. Therefore, the use of lithium in combination with a tricyclic antidepressant may be a promising way to improve efficacy in the treatment of resistant depression. A previous study demonstrated that repeated electroconvulsive stimuli decreased the duration of immobility in the forced swim test in rats treated chronically with ACTH [3]. Furthermore, we reported previously that chronic treatment with ACTH resulted in a decrease in cell proliferation in the SGZ of the hippocampal dentate gyrus [9]. Both electroconvulsive stimuli and chronic treatment with imipramine and lithium have been shown to increase cell proliferation in ACTH-treated rats [8] [9] [22]. Furthermore, it is well known that BDNF plays a role in the survival of neurons during hippocampal development and that this action may be

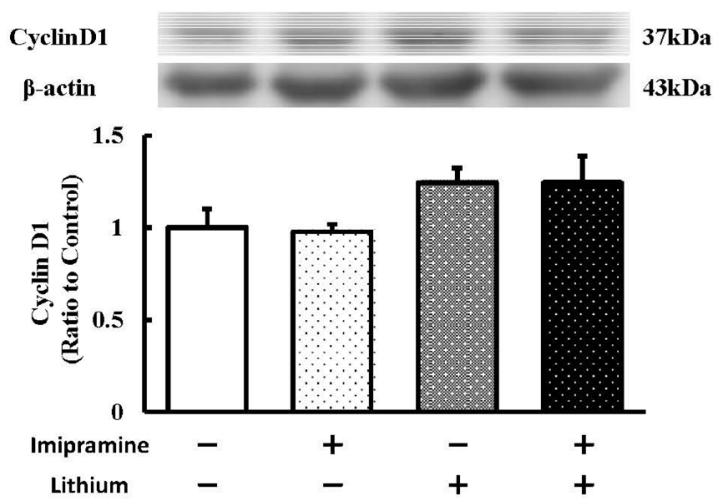

(a)

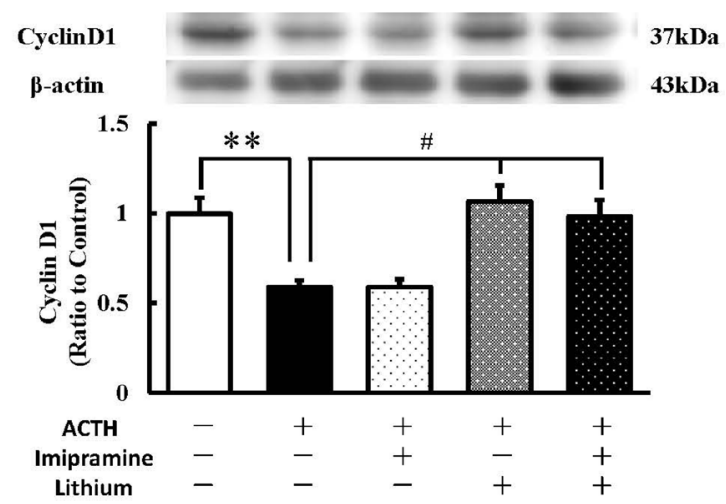

(b)

Figure 3. Effects of treatment with imipramine and lithium for 14 days on cyclin D1 protein levels in the hippocampus of saline-treated (a) and ACTH-treated rats (b). Each column is expressed as the mean \pm S.E.M.; $n=6$ - 8 per group. ${ }^{* *} P<0.01$ (vs control); ${ }^{\#} P<0.05$ (vs ACTH).

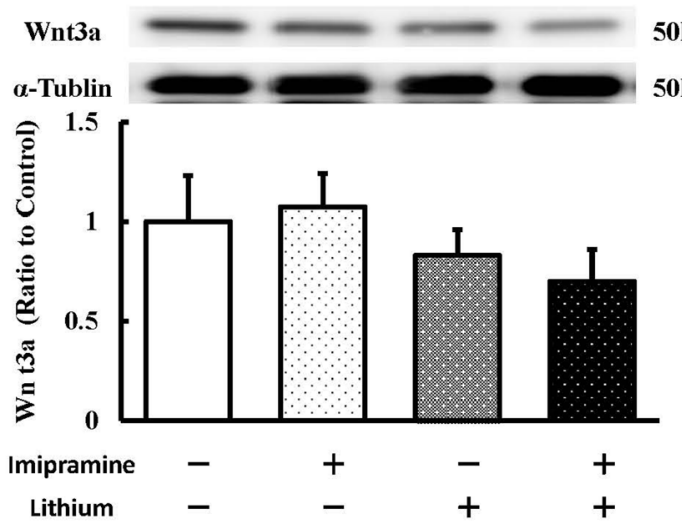

(a)

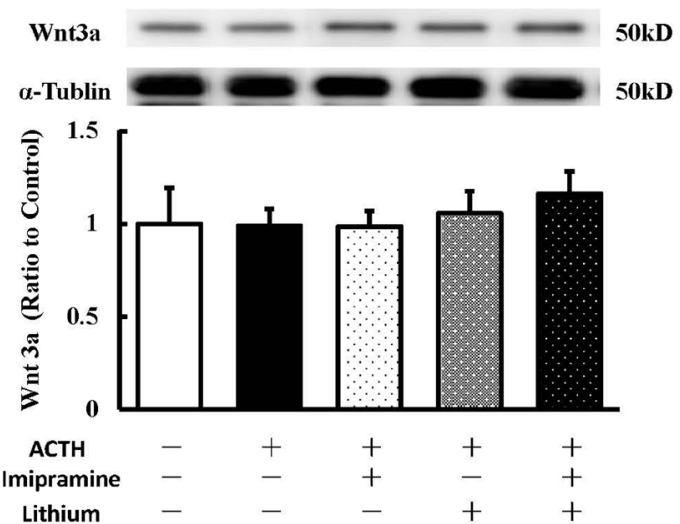

(b)

Figure 4. Effects of treatment with imipramine and lithium for 14 days on Wnt 3a protein levels in the hippocampus of saline-treated (a) and ACTH-treated rats (b). Each column is expressed as the mean \pm S.E.M.; $\mathrm{n}=6$ - 8 per group. 
related to its putative role in depression. Repeated electroconvulsive stimuli treatment increases mature-BDNF protein levels in the hippocampus of both saline-treated and ACTH-treated rat. This leads to an increase in pCREB levels and in the pCREB/CREB ratio in ACTH-treated rats. Therefore, the observed antidepressant-like effects of electroconvulsive stimuli may reflect enhanced cell proliferation in the hippocampus via activation of the CREB-BDNF pathway [22]. However, in the present study, hippocampal BDNF and CREB levels were not affected by imipramine and lithium treatment in saline- or ACTH-treated rats. These findings suggest that imipramine and lithium treatment did not activate CREB-BDNF signaling, indicating these pathways are unlikely to underlie the stimulatory effect of imipramine and lithium on the hippocampus.

Cyclin D1 is a molecule that links growth factor signaling with the cell cycle mechanism and is critical in regulating cellular progression through the G1 phase of the cell cycle. Cyclin D1 is a major transcriptional target of Wnt/ $\beta$-catenin signaling [23]. Among the several Wnt proteins, Wnt 3a has a dominant role in embryonic central nervous system development and is considered the principal regulator of neural stem cell proliferation and fate determination. Wnt 3a is expressed by adult hippocampal stem or progenitor cells, where it modulates the generation of newborn neurons in the hippocampal SGZ. To elucidate the involvement of the $\mathrm{Wnt} / \beta$-catenin pathway in hippocampal cell proliferation, we examined the effect of combined imipramine and lithium treatment on the expression of the key Wnt/ $\beta$-catenin signaling components, Wnt 3a and cyclin D1, in ACTH-treated rats.

Hippocampal cyclin D1 expression was decreased by treatment with ACTH, while lithium treatment significantly increased cyclin D1 expression in ACTH-treated rats. Our previous study demonstrated that treatment with ACTH for 14 days significantly decreases the number of BrdU-positive cells, an index of cell proliferation [9]. This effect was reversed via administration of lithium, albeitnot significantly. We also reported that chronic lithium treatment did not affect the duration of immobility in the forced swim test in ACTH-treated rats. Treatment with lithium also significantly increased cyclin D1 expression in ACTH-treated rats in this study. Lithium treatment may modestly enhance cell proliferation via increased cyclin D1 expression, although this would appear to be insufficient to produce antide pressive-like effects in ACTH-treated rats. Coadministration of imipramine and lithium significantly increases cyclin D1 expression in ACTH-treated rats. Our previous results suggested that chronic treatment with imipramine and lithium increases cell proliferation in ACTH-treated rats [8] [9]. Furthermore, chronic coadministration of imipramine and lithium significantly decreases the duration of immobility, even when given concurrently with ACTH [1]. Therefore, the observed antidepressant-like effects of imipramine and lithium may have been related to enhanced cell proliferation in the hippocampus via the activation of cyclin D1 expression. On the other hand, Wnt 3a protein levels were not affected by treatment with ACTH, imipramine, or lithium. Thus, Wnt 3a signaling may not contribute to imipramine and lithium-induced hippocampal cell proliferation in ACTH-treated rats. It is difficult to explain why Wnt 3a expression did not change in this study. $\beta$-catenin is a downstream effector of the $\mathrm{Wnt} / \beta$-catenin pathway. Stabilization of $\beta$-catenin results in persistent activation of signaling, which can increase the expression of genes that drive cell proliferation, such as cyclin D1 [23] [24]. $\beta$-catenin is reported to be expressed in the SGZ, and its nuclear localization suggests it may promote cyclin D1 transcription in SGZ cells [25]. This report also suggests that nuclear $\beta$ catenin can activate cyclin D1. From our preliminary assessment, ACTH treatment tended to decrease the expression of $\beta$-catenin. Thus, the effect of imipramine and lithium treatment to increase cyclin D1 expression seems not directly related to Wnt $/ \beta$-catenin signaling. Furthermore, $\beta$-catenin is an established marker of GSK-3 inactivation, because cytoplasmic levels are increased by inhibition of the enzyme [26]. Indeed, $\beta$-catenin, when sequentially phosphorylated by GSK-3 $\beta$, undergoes proteasomal degradation. Conversely, lithium prevents GSK-3 $\beta$-catalyzed phosphorylation of $\beta$-catenin, enabling $\beta$-catenin to accumulate and translocate to the nucleus, where it facilitates survival gene transcription [27] [28]. We confirmed that the expression of total and phosphorylated (Ser9, Tyr216) GSK3 $\beta$ was not affected by treatment with imipramine and lithium in saline- or ACTH-treated rats. Namely, it may be that cell proliferation in response to increased cyclin D1 levels involves different $\mathrm{Wnt} / \beta$-catenin signaling in ACTH-treated rats. Furthermore, we did not examine the effect of combined imipramine and lithium treatment on the expression of CREB-BDNF and $\mathrm{Wnt} / \beta$-catenin signaling at the other time point. Further studies are in progress to clarify these points.

\section{Conclusion}

Our previous results demonstrated that treatment with imipramine and lithium increases cell proliferation in the hippocampal dentate gyrus in ACTH-treated rats [8] [9]. In conclusion, imipramine and lithium treatment alters 
hippocampal expression of cyclin D1, but not Wnt 3a, in ACTH-treated rats. When combined with the results of previous studies, these results support the assertion that imipramine and lithium may improve the efficacy of treatment for resistant depression by triggering cell proliferation via cyclin D1.

\section{Acknowledgements}

This study was supported in part by a Grant-in-Aid for Scientific Research from the Ministry of Education, Culture, Sports, Science and Technology of Japan (No. 21590593).

\section{References}

[1] Kitamura, Y., Araki, H. and Gomita, Y. (2002) Influence of ACTH on the Effects of Imipramine, Desipramine and Lithium on Duration of Immobility of Rats in the Forced Swim Test. Pharmacology, Biochemistry and Behavior, 71, 63-69. http://dx.doi.org/10.1016/S0091-3057(01)00625-6

[2] Fink, M. (1990) How Does Convulsive Therapy Work? Neuropsychopharmacology, 3, 73-82.

[3] Li, B., Suemaru, K., Cui, R., Kitamura, Y., Gomita, Y. and Araki, H. (2006) Repeated Electroconvulsive Stimuli Increase Brain-Derived Neurotrophic Factor in ACTH-Treated Rats. European Journal of Pharmacology, 529, 114-121. http://dx.doi.org/10.1016/j.ejphar.2005.11.009

[4] Fuchs, E., Czeh, B. and Flugge, G. (2004) Examining Novel Concepts of the Pathophysiology of Depression in the Chronic Psychosocial Stress Paradigm in Tree Shrews. Behavioural Pharmacology, 15, 315-325. http://dx.doi.org/10.1097/00008877-200409000-00003

[5] Malberg, J.E. and Duman, R.S. (2003) Cell Proliferation in Adult Hippocampus Is Decreased by Inescapable Stress: Reversal by Fluoxetine Treatment. Neuropsychopharmacology, 28, 1562-1571. http://dx.doi.org/10.1038/sj.npp.1300234

[6] Kodama, M., Fujioka, T. and Duman, R.S. (2004) Chronic Olanzapine or Fluoxetine Administration Increases Cell Proliferation in Hippocampus and Prefrontal Cortex of Adult Rat. Biological Psychiatry, 56, 570-580. http://dx.doi.org/10.1016/j.biopsych.2004.07.008

[7] Santarelli, L., Saxe, M., Gross, C., Surget, A., Battaglia, F., Dulawa, S., Weisstaub, N., Lee, J., Duman, R., Arancio, O., Belzung, C. and Hen, R. (2003) Requirement of Hippocampal Neurogenesis for the Behavioral Effects of Antidepressants. Science, 301, 805-809. http://dx.doi.org/10.1126/science.1083328

[8] Doi, M., Miyazaki, I., Nagamachi, T., Shinomiya, K., Matsunaga, H., Sendo, T., Kawasaki, H., Asanuma, M., Gomita, Y. and Kitamura, Y. (2010) Effects of Imipramine and Lithium on the Suppression of Cell Proliferation in the Dentate Gyrus of the Hippocampus in Adrenocorticotropic Hormone-Treated Rats. Acta Medica Okayama, 64, 219-223.

[9] Kitamura, Y., Doi, M., Kuwatsuka, K., Onoue, Y., Miyazaki, I., Shinomiya, K., Koyama, T., Sendo, T., Kawasaki, H., Asanuma, M. and Gomita, Y. (2011) Chronic Treatment with Imipramine and Lithium Increases Cell Proliferation in the Hippocampus in Adrenocorticotropic Hormone-Treated Rats. Biological and Pharmaceutical Bulletin, 34, 77-81. http://dx.doi.org/10.1248/bpb.34.77

[10] Pencea, V., Bingaman, K.D., Wiegand, S.J. and Luskin, M.B. (2001) Infusion of Brain-Derived Neurotrophic Factor into the Lateral Ventricle of the Adult Rat Leads to New Neurons in the Parenchyma of the Striatum, Septum, Thalamus, and Hypothalamus. Journal of Neuroscience, 21, 6706-6717.

[11] Schinder, A.F., Berninger, B. and Poo, M. (2000) Postsynaptic Target Specificity of Neurotrophin-Induced Presynaptic potentiation. Neuron, 25, 151-163. http://dx.doi.org/10.1016/S0896-6273(00)80879-X

[12] Duman, R.S. and Monteggia, L.M. (2006) A Neurotrophic Model for Stress-Related Mood Disorders. Biological Psychiatry, 59, 1116-1127. http://dx.doi.org/10.1016/j.biopsych.2006.02.013

[13] Post, R.M. (2007) Role of BDNF in Bipolar and Unipolar Disorder: Clinical and Theoretical Implications. Journal of Psychiatric Research, 41, 979-990. http://dx.doi.org/10.1016/j.jpsychires.2006.09.009

[14] Kuipers, S.D., Trentani, A., van der Zee, E.A. and den Boer, J.A. (2013) Chronic Stress-Induced Changes in the Rat Brain: Role of Sex Differences and Effects of Long-Term Tianeptine Treatment. Neuropharmacology, 75, 426-436. http://dx.doi.org/10.1016/j.neuropharm.2013.08.018

[15] Baldin, V., Lukas, J., Marcote, M.J., Pagano, M. and Draetta, G. (1993) Cyclin D1 Is a Nuclear Protein Required for Cell Cycle Progression in G1. Genes and Development, 7, 812-821. http://dx.doi.org/10.1101/gad.7.5.812

[16] Matsushime, H., Quelle, D.E., Shurtleff, S.A., Shibuya, M., Sherr, C.J. and Kato, J.Y. (1994) D-Type Cyclin-Dependent Kinase Activity in Mammalian Cells. Molecular and Cellular Biology, 14, 2066-2076.

[17] Meirmanov, S., Nakashima, M., Kondo, H., Matsufuji, R., Takamura, N., Ishigaki, K., Ito, M., Prouglo, Y., Yamashita, S. and Sekine, I. (2003) Correlation of Cytoplasmic Beta-Catenin and Cyclin D1 Overexpression during Thyroid Car- 
cinogenesis around Semipalatinsk Nuclear Test Site. Thyroid, 13, 537-545. http://dx.doi.org/10.1089/105072503322238791

[18] Nakashima, M., Meirmanov, S., Naruke, Y., Kondo, H., Saenko, V., Rogounovitch, T., Shimizu-Yoshida, Y., Takamura, N., Namba, H., Ito, M., Abrosimov, A., Lushnikov, E., Roumiantsev, P., Tsyb, A., Yamashita, S. and Sekine, I. (2004) Cyclin D1 Overexpression in Thyroid Tumours from a Radio-Contaminated Area and Its Correlation with Pin1 and Aberrant Beta-Catenin Expression. Journal of Pathology, 202, 446-455. http://dx.doi.org/10.1002/path.1534

[19] Nelson, W.J. and Nusse, R. (2004) Convergence of Wnt, Beta-Catenin, and Cadherin Pathways. Science, 303, 14831487. http://dx.doi.org/10.1126/science.1094291

[20] Lee, S.M., Tole, S., Grove, E. and McMahon, A.P. (2000) A Local Wnt-3a Signal Is Required for Development of the Mammalian Hippocampus. Development, 127, 457-467.

[21] Chen, A.C., Shin, K.H., Duman, R.S. and Sanacora, G. (2001) ECS-Induced Mossy Fiber Sprouting and BDNF Expression Are Attenuated by Ketamine Pretreatment. Journal of ECT, 17, 27-32. http://dx.doi.org/10.1097/00124509-200103000-00006

[22] Kuwatsuka, K., Hayashi, H., Onoue, Y., Miyazaki, I., Koyama, T., Asanuma, M., Kitamura, Y. and Sendo, T. (2013) The Mechanisms of Electroconvulsive Stimuli in BrdU-Positive Cells of the Dentate Gyrus in ACTH-Treated Rats. Journal of Pharmacological Sciences, 122, 34-41. http://dx.doi.org/10.1254/jphs.13015FP

[23] Shtutman, M., Zhurinsky, J., Simcha, I., Albanese, C., D’Amico, M., Pestell, R. and Ben-Ze’ev, A. (1999) The Cyclin D1 Gene Is a Target of the Beta-Catenin/LEF-1 Pathway. Proceedings of the National Academy of Sciences of the United States of America, 96, 5522-5527. http://dx.doi.org/10.1073/pnas.96.10.5522

[24] Tetsu, O. and McCormick, F. (1999) Beta-Catenin Regulates Expression of Cyclin D1 in Colon Carcinoma Cells. Nature, 398, 422-426. http://dx.doi.org/10.1038/18884

[25] Kumar, D.U. and Devaraj, H. (2012) Expression of Wnt 3a, Beta-Catenin, Cyclin D1 and PCNA in Mouse Dentate Gyrus Subgranular Zone (SGZ): A Possible Role of Wnt Pathway in SGZ Neural Stem Cell Proliferation. Folia Biologica, 58, 115-120.

[26] Gould, T.D., Einat, H., Bhat, R. and Manji, H.K. (2004) AR-A014418, a Selective GSK-3 Inhibitor, Produces Antidepressant-Like Effects in the Forced Swim Test. International Journal of Neuropsychopharmacology, 7, 387-390. http://dx.doi.org/10.1017/S1461145704004535

[27] Jope, R.S. and Johnson, G.V. (2004) The Glamour and Gloom of Glycogen Synthase Kinase-3. Trends in Biochemical Sciences, 29, 95-102. http://dx.doi.org/10.1016/j.tibs.2003.12.004

[28] Takahashi-Yanaga, F. and Sasaguri, T. (2007) The Wnt/Beta-Catenin Signaling Pathway as a Target in Drug Discovery. Journal of Pharmacological Sciences, 104, 293-302. http://dx.doi.org/10.1254/jphs.CR0070024 
Scientific Research Publishing (SCIRP) is one of the largest Open Access journal publishers. It is currently publishing more than 200 open access, online, peer-reviewed journals covering a wide range of academic disciplines. SCIRP serves the worldwide academic communities and contributes to the progress and application of science with its publication.

Other selected journals from SCIRP are listed as below. Submit your manuscript to us via either submit@scirp.org or Online Submission Portal.
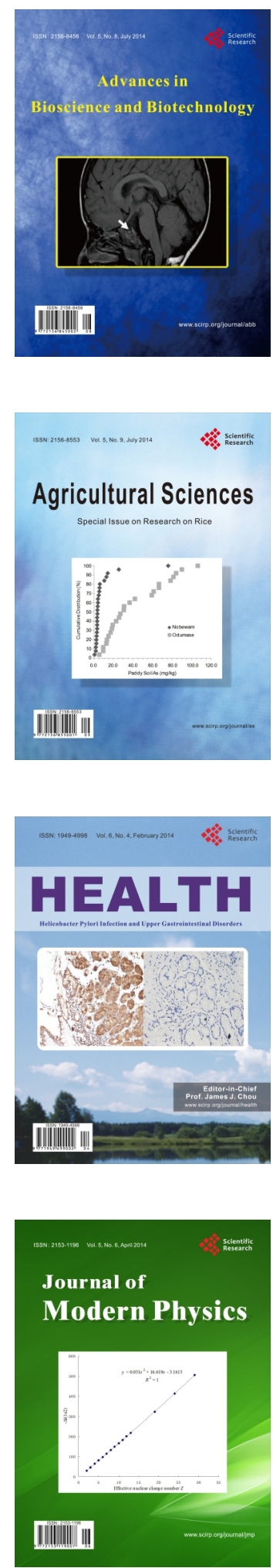
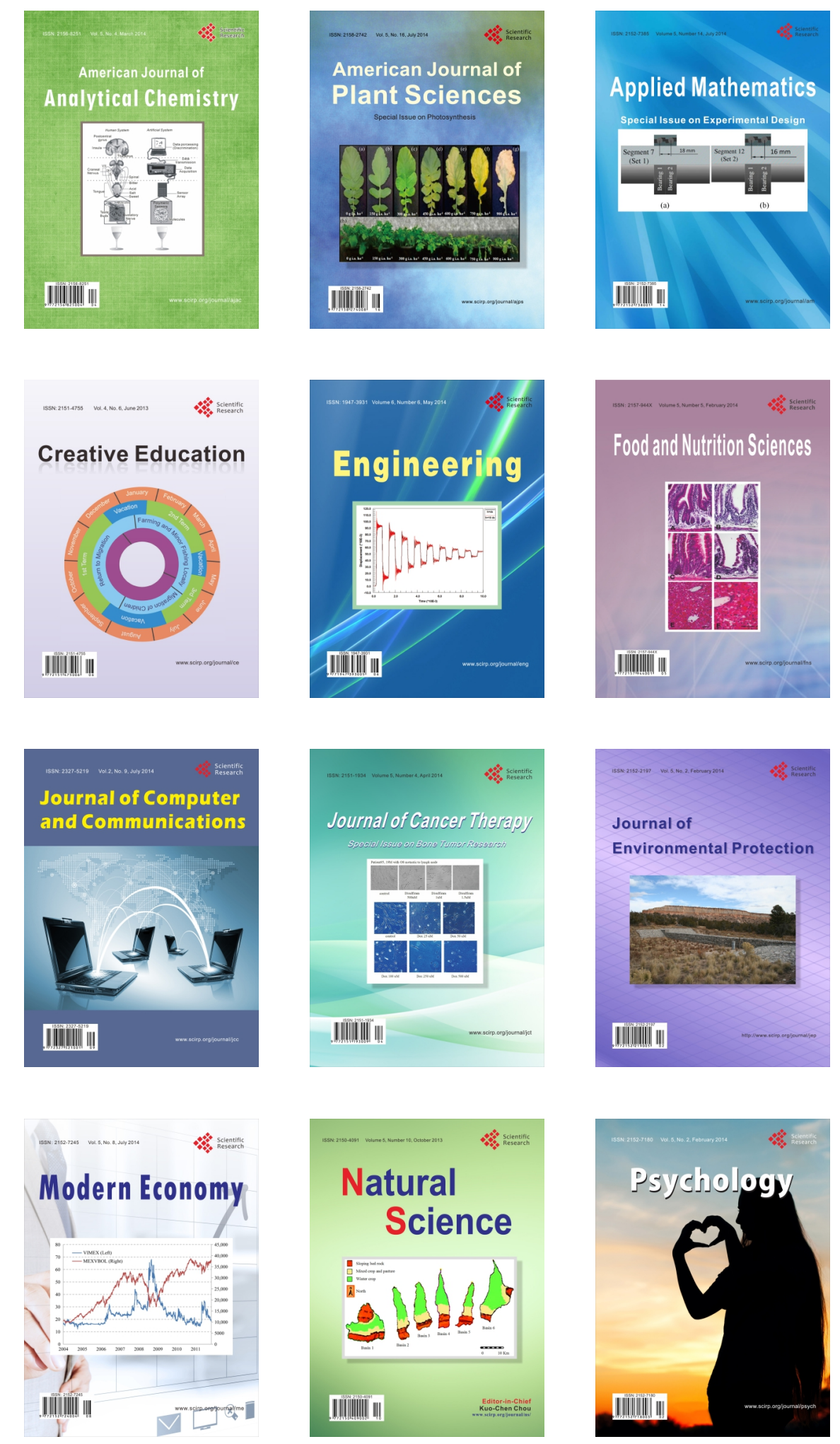